\title{
Publisher Correction: Elementary steps in electrical doping of organic semiconductors
}

\author{
Max L. Tietze 1,2,4, Johannes Benduhn', Paul Pahner', Bernhard Nell', Martin Schwarze (i) ${ }^{1}$, Hans Kleemann', \\ Markus Krammer ${ }^{3}$, Karin Zojer ${ }^{3}$, Koen Vandewal ${ }^{1,5}$ \& Karl Leo ${ }^{1}$
}

Correction to: Nature Communications https://doi.org/10.1038/s41467-018-03302-z, published online 21 March 2018

The original version of this Article contained an error in Eq. 1. A factor of ' $c$ ' was included in the right-hand term. This has been corrected in the PDF and HTML versions of the Article.

$$
p=N_{A}^{-}=c \frac{N_{A}}{1+\exp \left(\frac{E_{A}-E_{F}}{k_{B} T}\right)}
$$

The correct form of Eq. 1 is:

$$
p=N_{A}^{-}=\frac{N_{A}}{1+\exp \left(\frac{E_{A}-E_{F}}{k_{B} T}\right)}
$$

This has been corrected in the PDF and HTML versions of the Article.

Published online: 12 June 2018

\begin{abstract}
(c) Open Access This article is licensed under a Creative Commons Attribution 4.0 International License, which permits use, sharing, adaptation, distribution and reproduction in any medium or format, as long as you give appropriate credit to the original author(s) and the source, provide a link to the Creative Commons license, and indicate if changes were made. The images or other third party material in this article are included in the article's Creative Commons license, unless indicated otherwise in a credit line to the material. If material is not included in the article's Creative Commons license and your intended use is not permitted by statutory regulation or exceeds the permitted use, you will need to obtain permission directly from the copyright holder. To view a copy of this license, visit http://creativecommons.org/licenses/by/4.0/.
\end{abstract}

(C) The Author(s) 2018

\footnotetext{
${ }^{1}$ Dresden Integrated Center for Applied Physics and Photonic Materials, Technische Universität Dresden, Nöthnitzer Strasse 61, 01187 Dresden, Germany ${ }^{2}$ Physical Science and Engineering Division, KAUST Solar Center, King Abdullah University of Science and Technology, Thuwal 23955-6900, Saudi Arabia. ${ }^{3}$ NAWI Graz, Institute of Solid State Physics, Graz University of Technology, Petersgasse 16, 8010 Graz, Austria. ${ }^{4}$ Present address: Department of Microbial and Molecular Systems, Centre for Surface Chemistry and Catalysis, KU Leuven-University of Leuven, Celestijnenlaan $200 \mathrm{~F}, \mathrm{~B}-3001$ Leuven, Belgium. ${ }^{5}$ Present address: Instituut voor Materiaalonderzoek, Hasselt University, Wetenschapspark 1, 3590 Diepenbeek, Belgium. The original article can be found online at https://doi.org/10.1038/s41467-018-03302-z. Correspondence and requests for materials should be addressed to M.L.T. (email: max.tietze@iapp.de) or to K.L. (email: karl.leo@iapp.de)
} 